\title{
Desmoid-type fibromatosis of the head and neck in children: a case report and review of the literature
}

\author{
Hidetaka Miyashita', Seiji Asoda', Tomoya Soma', Kanako Munakata', Masaki Yazawa², Taneaki Nakagawa \\ and Hiromasa Kawana ${ }^{1 *}$
}

\begin{abstract}
Background: Desmoid-type fibromatosis is defined as an intermediate tumor that rarely occurs in the head and neck of children. There is no doubt as to the value of complete surgical excision for desmoid-type fibromatosis. However, in pediatric patients, surgeons may often be concerned about making a wide excision because of the potential for functional morbidity. Some studies have reported a lack of correlation between margin status and recurrence. Therefore, we discussed our findings with a focus on the state of surgical margins.
\end{abstract}

Case presentation: We report an unusual case of a 9-month-old Japanese girl who prior to presenting at our hospital underwent debulking surgery twice with chemotherapy for desmoid-type fibromatosis of the tongue at another hospital. We performed a partial glossectomy and simultaneous reconstruction with local flap and achieved microscopic complete resection. We also reviewed available literature of pediatric desmoid-type fibromatosis in the head and neck.

Conclusions: We described successful treatment for the refractory case of pediatric desmoid-type fibromatosis. The review results showed that some microscopic incomplete resections of tumors in pediatric patients with desmoid-type fibromatosis tended to be acceptable with surgical treatment.

Keywords: Desmoid, Fibromatosis, Children, Head and neck, Decision-making, Tongue, Case report

\section{Background}

According to the World Health Organization's classification of head and neck tumors [1], desmoid-type fibromatosis (DF) is defined as a borderline tumor of soft tissues that has low malignant potential. DF is characterized by local aggressiveness with an approximate $20 \%$ local recurrence rate, but without metastasis [1]. The annual incidence of DF is presumed to be 0.2 to 0.4 per 100,000 individuals [2]. Among cases of DF, 7 to $15 \%$ of tumors occur in the head and neck [1, 3, 4]. A paper on the European Organisation for Research and Treatment of Cancer (EORTC)/Soft Tissue and Bone Sarcoma Group's position on DF reported that a "watch and wait strategy" is the first choice in the treatment of DF in all

\footnotetext{
* Correspondence: kawana@keio.jp

${ }^{1}$ Division of Oral and Maxillofacial Surgery, Department of Dentistry and Oral Surgery, School of Medicine, Keio University, 35 Shinanomachi, Shinjyuku-ku, Tokyo 160-8582, Japan

Full list of author information is available at the end of the article
}

populations and that resection with a clear margin should be considered to be a treatment option if postoperative morbidity is acceptable [5]. Although complete resection (negative microscopic margin; $\mathrm{CR}$ ) of the tumor is thought to be the reference standard for successful treatment in patients with DF uncontrolled by other treatment approaches, resection in the head and neck region is often difficult because of the presence of vital structures [6]. This problem is worse in pediatric patients. In pediatric patients with DF uncontrolled by non-surgical treatments, surgeons sometimes are concerned about performing wide resections because of the high potential of postoperative morbidity. When a large tumor exists close to a vital structure, surgery with an adequate safety margin may be challenging. Although some successful cases with incomplete resection or without surgery have been reported [7-12], a randomized trial of treatment strategies has not yet been reported. 


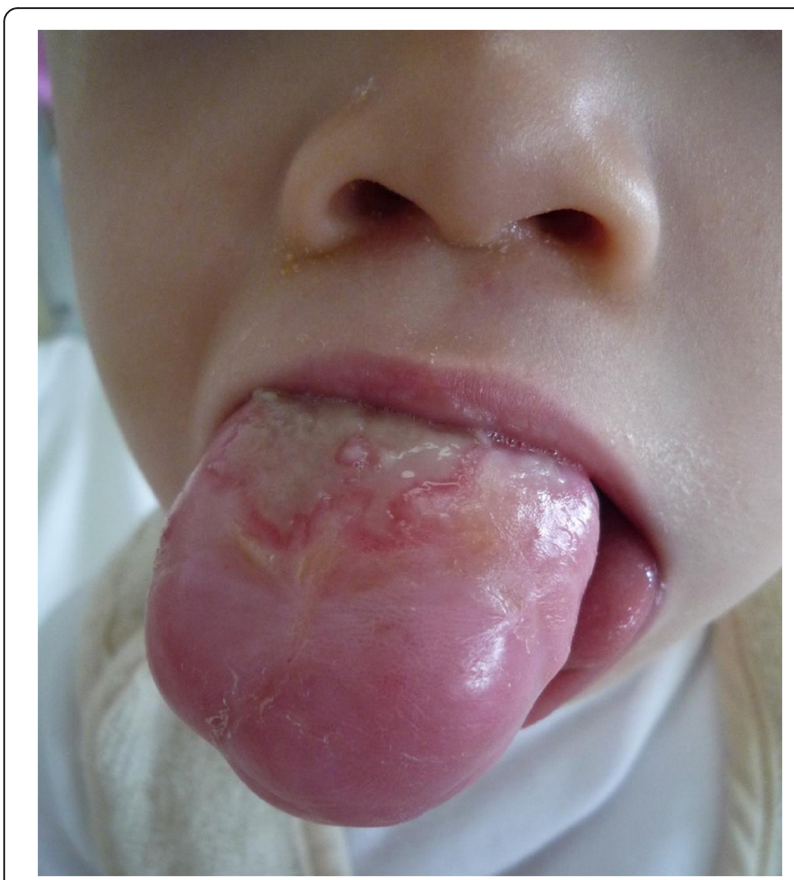

Fig. 1 The patient could not close her mouth completely because of the presence of a part of the tumor outside her mouth. The maximum tumor size reached $5 \mathrm{~cm}$

In our view, many surgeons have limited experience on how to decide on performing ablation in pediatric patients with DF. Thus, we reviewed the available literature to determine various factors that could influence treatment decisions in pediatric DF. In particular, we focused on the correlation between margin status and disease condition and if there are differences in disease condition between microscopic incomplete resection (microscopic positive margin but no remaining gross tumor; MIR) and gross incomplete resection. As part of our study, we included a case involving a 9-month-old Japanese girl with DF of the tongue who was surgically treated at our oral and maxillofacial surgery division.

\section{Case presentation}

A 9-month-old Japanese girl was referred to our hospital because of a growing tumor on her tongue. Her family noted the mass in her tongue at the age of 3 months. She twice underwent debulking surgery with medical treatment, involving NSAIDs, vinblastine plus methotrexate, and vinblastine plus actinomycin-d at another hospital. The analysis of a resected specimen led to the diagnosis of DF at the age of 7 months. However, the tumor was not controlled. When she was brought to our hospital, the tumor rapidly increased, and a portion popped out of her mouth (Fig. 1). She could not close her mouth completely, but swallowing dysfunction and upper respiratory infection was not observed. Her swallowing function was complemented by trick motion of the unaffected side. She had no history of any disorders associated with DF. A whole body computed tomography examination revealed no signs of any other tumoral lesions. On the basis of radiological examinations and the clinical course, we made the decision to perform radical surgery. Magnetic resonance imaging (MRI) with contrast enhancement showed the mass (Fig. 2). A partial glossectomy with a 5-mm safety margin and simultaneous reconstruction with a local flap were performed under general anesthesia (Fig. 3). After excision, primary wound closure was performed without any graft while being careful to preserve postoperative function. We confirmed a microscopic $\mathrm{CR}$ in a pathological examination of the surgical specimen. Her postoperative progress was extremely good, and no functional morbidity, such as eating dysfunction or dysphonia, was observed. She had no indication of recurrence after a year (Fig. 4).

\section{Discussion}

We performed a review of the literature by searching PubMed and using the keywords "desmoid," "fibromatosis,"

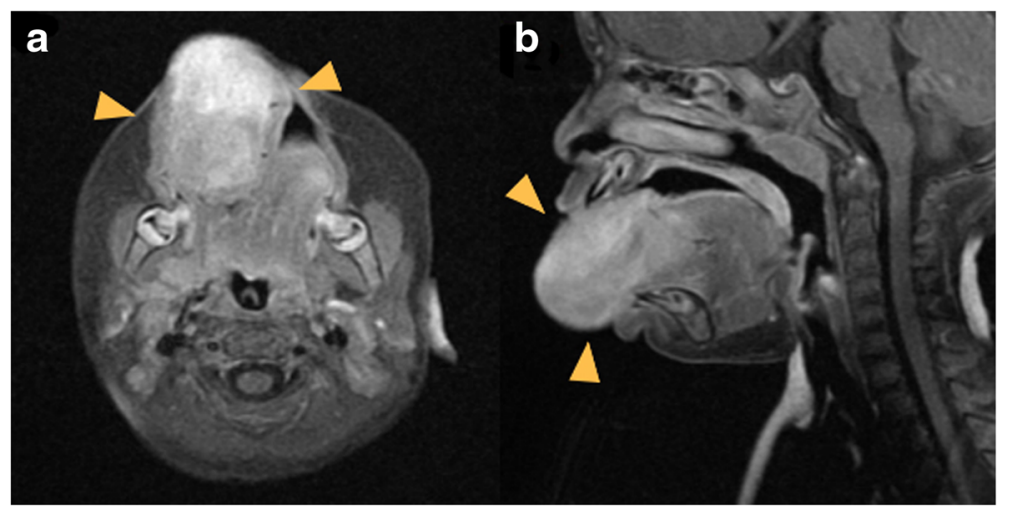

Fig. 2 a Magnetic resonance imaging (MRI) showing huge mass with contrast enhancement in the right side. b MRI of saggital plane did not show the posibility of infiltration into the root of the tongue. Arrows indicate the areas of tumor with contrast enhancement 


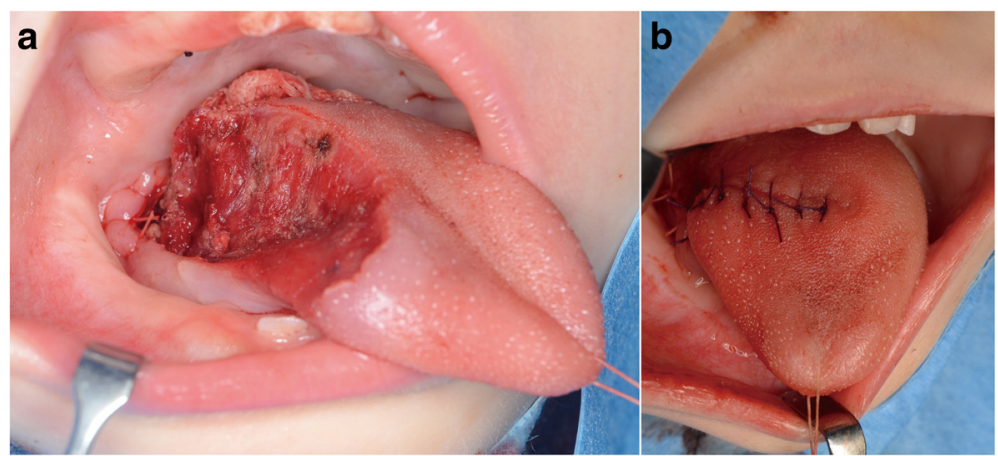

Fig. 3 a A partial glossectomy with a 5-mm safety margin was performed. b We performed simultaneous reconstruction with a local flap and rotation of the anterior tongue on the unaffected side into the tongue defect on the affected side

and "pediatric." We found 97 articles from 1982 to 2015 when we searched cross-sectionally. The established exclusion criteria were as follows: details in individual cases not described, patients who were $>19$-years old, reports not written in English, and tumor sites not in the head and neck. We examined the following factors in all cases: age, sex, tumor site, tumor size, treatment, margin status, recurrence, complication, disease condition, and follow-up duration. The descriptive terms of incomplete resection (MIR), residual tumor, positive, and $\mathrm{CR}$, which relate to margin status, were defined as follows: MIR, microscopic positive margin but no remaining gross tumor; residual tumor, remaining gross tumor; positive, positive resection margin, but we could not determine if it was MIR or a residual tumor; CR, negative microscopic margin; and NR, data not shown. The cases were reviewed in detail and are discussed in this case report.

We identified 141 patients with DF in the head and neck [7, 8, 13-72]. Age at diagnosis ranged from birth to 18 years, and the mean age was 4 years 3 months. The sex of the patient was reported in $92 \%$ of all cases $(67$ males and 63 females). Regarding the tumor sites, a majority of tumors arose from the mandible ( $25 \%)$. Other

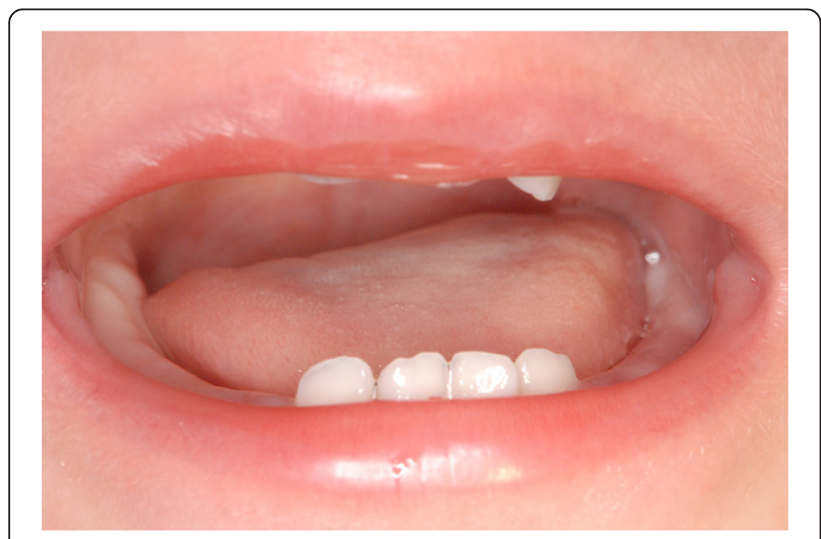

Fig. 4 Intraoral findings after a year postoperatively
Table 1 Primary tumor sites

\begin{tabular}{ll}
\hline Location of tumors & The number of patients \\
\hline Mandible & $35(2)$ \\
Submandibular area & $22(2)$ \\
Neck & $13(5)$ \\
Tongue & $12(3)$ \\
Cervical paraspinal area & $8(7)$ \\
Infratemporal fossa & $8(3)$ \\
Parapharyngeal space & $7(1)$ \\
Maxilla & $7(2)$ \\
Peritracheal area & $3(3)$ \\
Paranasal sinus (ethmoidal, sphenoid) & $3(1)$ \\
Floor of mouth & $2(1)$ \\
Forehead skin & 2 \\
Lip & 2 \\
Parotid gland & 2 \\
Parietal & 2 \\
Nuchal area & $2(1)$ \\
Cervicothoracic & $1(1)$ \\
Suprahyoid & $1(1)$ \\
Canthus & 1 \\
Cheek & 1 \\
Hypoglossal & 1 \\
Oropharynx & 1 \\
Supopharynx & 1 \\
Scalp skin & 1 \\
Theriorbital & 1 \\
\hline
\end{tabular}

The numbers within parentheses are the numbers of recurrences in patients with surgery 
sites were as follows: submandibular area, infratemporal fossa, neck, peritracheal area, and paraspinal area. A list of tumor sites is presented in Table 1 . We were able to identify the tumor size in $78(55 \%)$ patients. The average tumor size was $43.6 \mathrm{~mm}$ (range, 5 to $100 \mathrm{~mm}$ ). Surgery was performed in $125(88.6 \%)$ patients during the treatment period, and the remaining patients were treated only with chemotherapy (12 patients), the watch and wait strategy (3 patients), or a combination of radiation and chemotherapy (1 patient). Margin status was identified in $78(62.4 \%)$ of the 125 patients. The number of patients who had MIR, residual tumors, positive status, and CRs was $24,19,19$, and 16, respectively. Recurrence was observed in 34 $(27.2 \%)$ of the 125 patients with surgery. The most common margin status was residual, which was observed in 14 patients. The number of patients who had positive status, MIR, CR, and NR was $7,8,1$, and 4, respectively (Fig. 5). Postoperative complications were identified in detail in 13 patients. Trismus was the most common complication $(n=6)$. Two patients experienced secondary papillary carcinoma due to radiation therapy. Osteomyelitis $(n=2)$, slight ptosis due to a sectioned facial nerve $(n=1)$, restrictive neck movement $(n=1)$, and Claude-Bernard-Horner syndrome $(n=1)$ were confirmed. The disease condition was identified in 126 of the 140 patients (Fig. 6). Details were not reported for 15 patients. Ninety-seven patients showed no evidence of disease (NED). Stable disease (SD), partial response (PR), progressive disease (PD), and death occurred in $15,6,5$, and 3 patients, respectively. The average follow-up duration was 53.3 months (range, 2 to 298 months).

The most common tumor site in the recurrent patients was the cervical paraspinal region (seven patients). The next most common tumor site was the neck (five patients). Other sites we could identify were as follows: peritracheal area, infratemporal fossa, submandibular area, and tongue. All tumor sites in the recurrent patients are shown in Table 1. The recurrence rates for each margin status were MIR, 7 (29.1 \%) of 24; residual, 14 (73.6 \%) of 19; positive, 8 (42.1\%) of 19 ; and CR, 1 (6.2\%) of 16 patients (Fig. 7). There were 29 patients with positive margins without recurrence; "positive" status as used here includes MIR, residual, and positive status. Adjuvant therapies for these patients were as follows. In the case of MIR without recurrence $(n=15)$, observation $(n=9)$, chemotherapy $(n=4)$, and radiation $(n=2)$ were performed. In the case of residual tumors without recurrence $(n=4)$, all patients spontaneously regressed. In positive patients without recurrence $(n=10)$, observation $(n=3)$, only chemotherapy $(n=5)$, and administration of NSAIDs plus chemotherapy $(n=2)$ were performed.

In recurrent patients, the relationship between margin status $(n=31)$ and disease condition was confirmed as follows (Fig. 8). In the case of MIR ( $n=7)$, six (85.7\%) of seven patients had NED because second surgeries had been performed. One of the seven patients with SD was treated only with chemotherapy. In the case of residual tumors $(n=14)$, there were two patients with NED, seven with SD, two with PR, two with PD, and one who died. Only $14.2 \%$ of the patients showed controlled NED. In the case of positive status $(n=9)$, there were two patients with NED, five with SD, one with PD, and one who died. There was NED in $11.1 \%$ of the patients. The patient having CR with recurrence $(n=1)$ had controlled NED. The patients having MIR (85.7 \%) and CR (100 \%) with recurrence had high rates of NED. It is notable that all recurrent patients with controlled NED were rescued by second surgery.

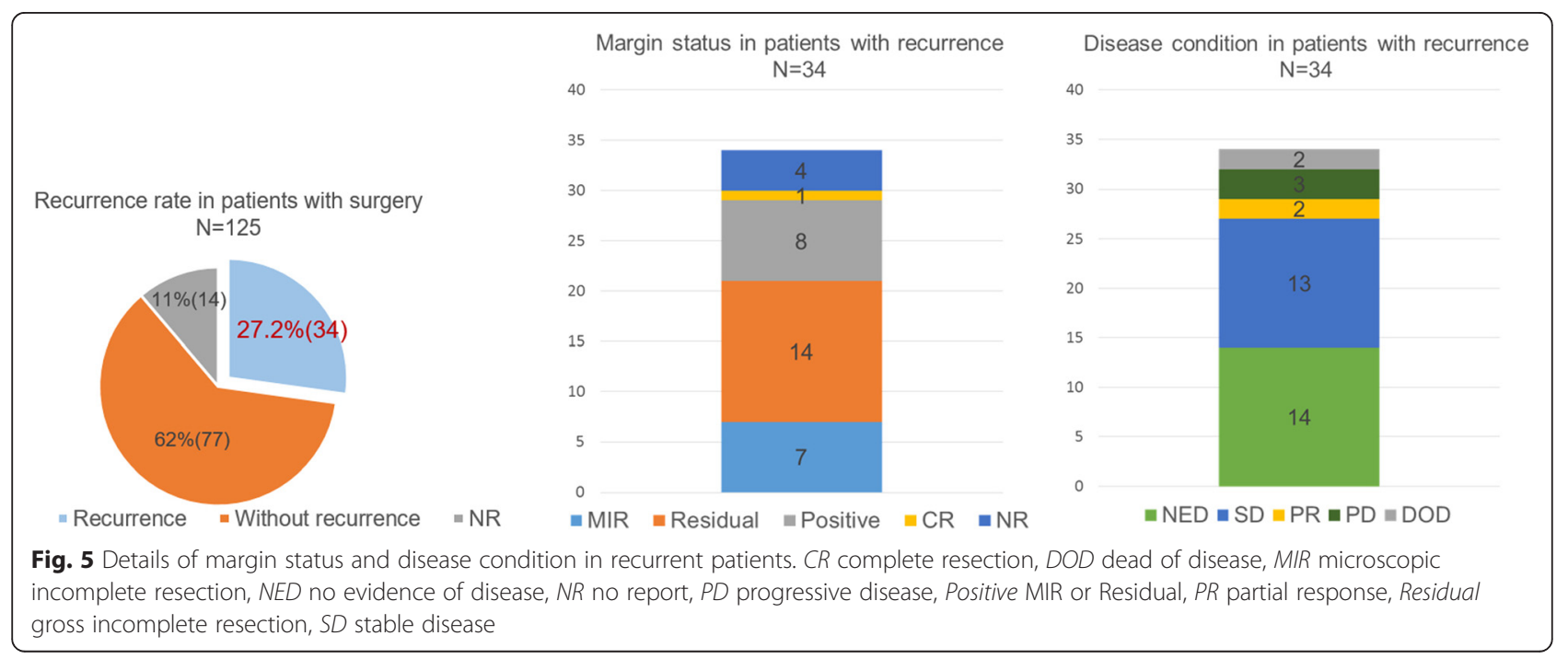




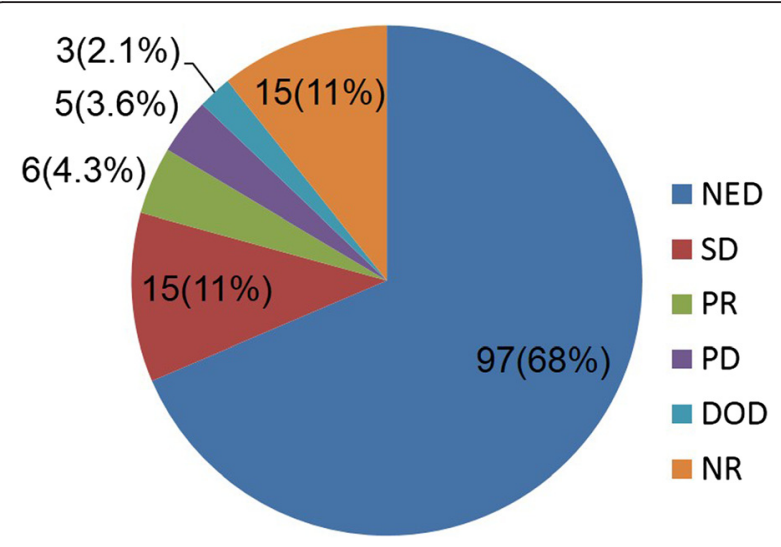

Fig. 6 Disease condition in all patients $(n=141)$. DOD dead of disease, NED no evidence of disease, NR no report, $P D$ progressive disease, $P R$ partial response, SD stable disease

The number of patients for each disease condition in all recurrent patients $(n=34)$ with surgery was 14 with NED, 13 with SD, 2 with PR, 3 with PD, and 2 who died (Fig. 5). Of all recurrent patients with surgery, $41.1 \%$ had controlled NED. Consequently, in all cases in which surgery was performed, 91 (72.8\%) patients had controlled NED. The mean follow-up duration for patients with surgery was 53.3 months. The result of our literature review was summarized in Table 2.

The main finding of our study was that the tumor control rate tended to be high in cases of MIR. Moreover, there were 29 margin-positive patients who were without recurrence. A majority of these patients had MIR ( $n=15)$, and $15(62.5 \%)$ of 24 patients with MIR did not show recurrence. In our view, these results suggest that a finding of MIR could be acceptable during local aggressive DF treatment in children. A paper on EORTC's position on DF in all populations [5] proposed that if positive microscopic surgical margins were found at a pathological examination, no further treatment should be considered. Our review results supported this position in pediatric patients with head and neck DF. Wide resection may induce long-term functional morbidity, especially in children, and may require reconstruction. Even though microvascular reconstruction is useful in pediatric patients for well-experienced surgeons $[73,74]$, the decision to proceed with wide resection should be carefully considered; the results of this study may be useful when making decisions in such cases.

If progression occurs after the watch and wait strategy has been pursued, medical therapy is clearly recommended in patients with head and neck DF according to the paper on EORTC's position [5]. However, a standard treatment is yet to be established. Previous prospective studies in pediatric patients with DF, including a phase II trial of vinblastine plus methotrexate and tamoxifen plus NSAIDs, have reported that the $\mathrm{CR}$ and $\mathrm{PR}$ rates were $19.2 \%$ and $8 \%$, respectively $[75,76]$. Even when CRs are included, the total response rate is insufficient. The restrictive effectiveness of chemotherapy regimens, such as liposomal doxorubicin, anthracycline-based regimen, imatinib, and sorafenib, in the total population has been confirmed [77-80]. However, no high-grade evidence study (that is, a randomized phase III trial) has been reported. In the present study, in only one patient, chemotherapy using Adriamycin (doxorubicin)

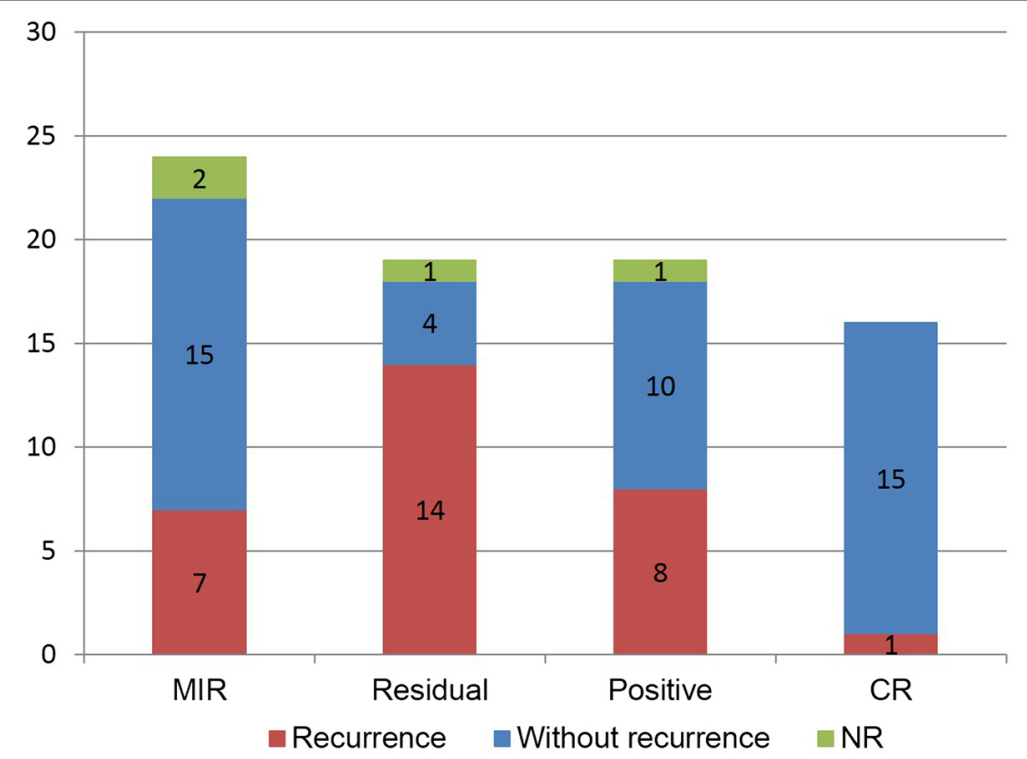

Fig. 7 The number of recurrences for each margin status. CR complete resection, MIR microscopic incomplete resection, NR no report, Positive microscopic incomplete resection or residual gross incomplete resection, Residual gross incomplete resection 


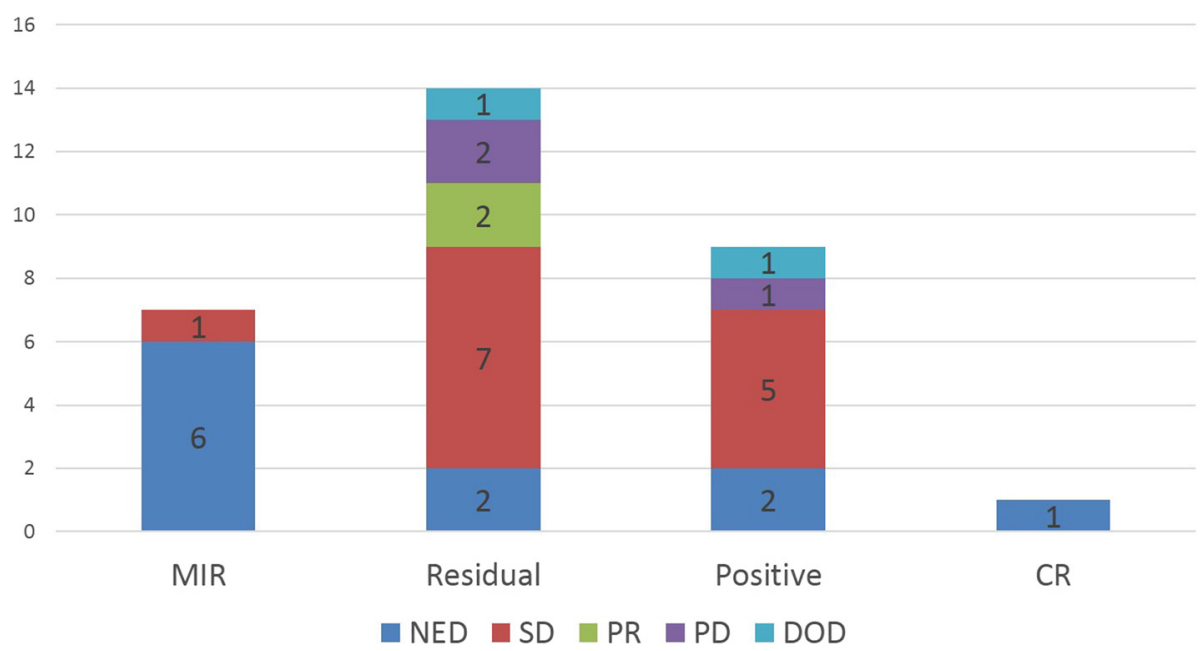

Fig. 8 Relationship between margin status and disease condition in the recurrent patients. $C R$ complete resection, DOD dead of disease, MIR microscopic incomplete resection, NED no evidence of disease, PD progressive disease, Positive microscopic incomplete resection or residual gross incomplete resection, $P R$ partial response, Residual gross incomplete resection, SD stable disease

and dacarbazine achieved CR. Furthermore, in the recurrent patients, there were none with controlled NED who had been treated only with subsequent chemotherapy. They were rescued by second surgery. Therefore, at present, the therapeutic effect of chemotherapy may be limited in pediatric DF treatment. A randomized trial would be needed to confirm the efficacy of chemotherapy in pediatric DF treatment.

Table 2 The results of literature review

\begin{tabular}{l}
\hline Summary of literature review \\
\hline The number of patients \\
Mean age (years) \\
Gender \\
Male \\
Female \\
NR \\
Treatment \\
$\quad$ With surgery \\
$\quad$ Without surgery \\
Recurrence rate (\%) in patients with surgery \\
Average follow-up duration (months) \\
Abstraction of principal information \\
1. In the margin positive patients ( $N=62$ ), 29 patients did not show \\
recurrence. After initial surgery, 16 of them did not need additional \\
treatment. \\
2. In the patients having MIR, the recurrence rate (29.1 \%) is lower and \\
the NED rate (85.7 \%) is higher than other margin positive status. \\
3. In the recurrent patients who had NED, all of them were treated with \\
second surgery. \\
4. We identified postoperative complications in detail in 13 patients \\
including radiation-induced secondary papillary carcinoma.
\end{tabular}

MIR microscopic incomplete resection, NED no evidence of disease, NR no report
Although previous reports have indicated that treatments with surgery and radiotherapy in all populations improve the progression-free survival rate relative to that of surgery alone $[3,81]$, the use of radiotherapy during DF treatment is controversial. However, in pediatric patients, radiotherapy may be less available because of late adverse effects and lower effectiveness. Side effects including secondary carcinoma related to radiotherapy for DF in pediatric and young-adult patients have been reported [53, 82]. A medium-sized retrospective study involving 30 patients in a single institution who were treated with radiotherapy for pediatric and young-adult DF reported a lower regional control rate for patients who were $<18$-years old (20\%) than for those who were 18 to 30 -years old (63\%) [53]. In the present study, 13 patients received radiotherapy, and complications were identified in three patients: two patients developed secondary papillary thyroid cancer after total doses of 55 Gy and 50 to 60 Gy (not specified), and one developed osteoradionecrosis after a total dose of 55 Gy. There is no clearly standardized evidence-based radiation strategy for pediatric head and neck DF. Some refractory patients may need radiation therapy. However, it may not be reasonable to routinely consider radiotherapy for pediatric patients with DF having positive margins.

\section{Conclusions}

The present study cannot provide the same level of evidence as could be obtained in a prospective study, and no single institution retrospective studies were included in the review because details were lacking. However, we believe that the collected results can be helpful in making treatment decisions, especially those involving 
surgery, in pediatric patients with DF. In summary, microscopic positive margins in pediatric DF did not always lead to an uncontrolled condition. In some patients, such findings appeared to be acceptable in pediatric patients with local aggressive DF. Nevertheless, further evidence-based approaches are needed before DF treatment strategies can be standardized.

\section{Abbreviations}

CR, complete resection; DF, desmoid-type fibromatosis; EORTC, European Organisation for Research and Treatment of Cancer; MIR, microscopic incomplete resection; MRI, magnetic resonance imaging; NED, no evidence of disease; NR, data not shown; PD, progressive disease; $\mathrm{PR}$, partial response; SD, stable disease

\section{Authors' contributions}

$H K$ and $H M$ drafted and critically reviewed the manuscript. HK, HM, and MY performed the operation and clinical follow-up of the patient. TS and KM contributed to data collection and literature search. SA and TN conceived of the study and participated in its design. All authors read and approved the final manuscript.

\section{Competing interests}

The authors declare that they have no competing interests.

\section{Consent}

Written informed consent was obtained from the patient's legal guardians for publication of this case report and any accompanying images. A copy of the written consent is available for review by the Editor-in-Chief of this journal.

\section{Author details}

'Division of Oral and Maxillofacial Surgery, Department of Dentistry and Oral Surgery, School of Medicine, Keio University, 35 Shinanomachi, Shinjyuku-ku, Tokyo 160-8582, Japan. Department of Plastic and Reconstructive Surgery, School of Medicine, Keio University, 35 Shinanomachi, Shinjyuku-ku, Tokyo 160-8582, Japan

Received: 14 March 2016 Accepted: 11 May 2016 Published online: 10 June 2016

\section{References}

1. Barnes L, Eveson JW, Reichart P, Sidransky D. World Health Organization classification of tumors. Pathology and genetics of head and neck tumors. Lyon: IARC; 2005.

2. Reitamo JJ, Scheinin TM, Hayry P. The desmoid syndrome. New aspects in the cause, pathogenesis and treatment of the desmoid tumor. Am J Surg. 1986:151:230-7.

3. Baumert BG, Spahr MO, Von Hochstetter A, et al. The impact of radiotherapy in the treatment of desmoid tumours. An international survey of 110 patients. A study of the Rare Cancer Network. Radiat Oncol. 2007;2:12.

4. Tse GM, Chan KF, Ahuja AT, King AD, Pang PC, To EW. Fibromatosis of the head and neck region. Otolaryngol Head Neck Surg. 2001;125:516-9.

5. Kasper B, Baumgarten C, Bonvalot $S$, et al. Management of sporadic desmoid-type fibromatosis: a European consensus approach based on patients' and professionals' expertise - a sarcoma patients EuroNet and European Organisation for Research and Treatment of Cancer/Soft Tissue and Bone Sarcoma Group initiative. Eur J Cancer. 2015;51:127-36.

6. de Bree $\mathrm{E}$, Zoras O, Hunt $\mathrm{J}$, et al. Desmoid tumors of the head and neck: a therapeutic challenge. Head Neck. 2014;36:1517-26.

7. Humar A, Chou S, Carpenter B. Fibromatosis in infancy and childhood: the spectrum. J Pediatr Surg. 1993;28:1446-50

8. Woltsche N, Gilg MM, Fraissler $L$, et al. Is wide resection obsolete for desmoid tumors in children and adolescents? Evaluation of histological margins, immunohistochemical markers, and review of literature. Pediatr Hematol Oncol. 2015;32:60-9.
9. Gronchi A, Casali PG, Mariani L, et al. Quality of surgery and outcome in extra-abdominal aggressive fibromatosis: a series of patients surgically treated at a single institution. J Clin Oncol. 2003;21:1390-7.

10. Honeyman JN, Theilen TM, Knowles MA, et al. Desmoid fibromatosis in children and adolescents: a conservative approach to management. J Pediatr Surg. 2013;48:62-6.

11. Lev D, Kotilingam D, Wei $C$, et al. Optimizing treatment of desmoid tumors. J Clin Oncol. 2007;25:1785-91.

12. Wang CP, Chang YL, Ko JY, Cheng CH, Yeh CF, Lou PJ. Desmoid tumor of the head and neck. Head Neck. 2006;28:1008-13.

13. Alebouyeh M, Moussavi F, Tabari AK, Vossough P. Aggressive intraabdominal fibromatosis in children and response to chemotherapy. Pediatr Hematol Oncol. 2005:22:447-51.

14. Ayala AG, Ro JY, Goepfert H, Cangir A, Khorsand J, Flake G. Desmoid fibromatosis: a clinicopathologic study of 25 children. Semin Diagn Pathol. 1986;3:138-50

15. Bisogno G, Tagarelli A, Stramare R, Beltrame V, Carli M. Hydroxyurea treatment can avoid the need for aggressive surgery in pediatric fibromatosis. J Pediatr Hematol Oncol. 2013:35:e171-3.

16. Buitendijk $S$, van de Ven $C P$, Dumans $T G$, et al. Pediatric aggressive fibromatosis: a retrospective analysis of 13 patients and review of literature. Cancer. 2005;104:1090-9.

17. Burlini D, Conti G, Bardellini E, Amadori F. Rare case of desmoid-type fibromatosis of the mandibular region in a child: diagnosis and surgical management. Eur J Paediatr Dent. 2013;14:333-4.

18. Caglar K, Ozyonum H, Akalin M, Balci S. Effective treatment of multifocal aggressive fibromatosis with low-dose chemotherapy. Turk J Pediatr. 2006:48:365-8

19. Carr RJ, Zaki GA, Leader MB, Langdon JD. Infantile fibromatosis with involvement of the mandible. Br J Oral Maxillofac Surg. 1992;30:257-62.

20. Crawley MB, Anand SM, Clain JB, Scherl S, Buchbinder D, Urken ML. Trismus release in a pediatric patient using a parascapular free flap reconstruction following desmoid tumor resection. Laryngoscope. 2013;123:1451-4.

21. De Corti F, Avanzini S, Cecchetto G, et al. The surgical approach for cervicothoracic masses in children. J Pediatr Surg. 2012;47:1662-8.

22. De Santis D. Fibromatosis of the mandible: case report and review of previous publications. Br J Oral Maxillofac Surg. 1998;36:384-8.

23. Ekinci S, Karnak I, Tanyel FC. Infantile fibromatosis of the sternocleidomastoid muscle mimicking muscular torticollis. J Pediatr Surg. 2004;39:1424-5.

24. Falco NA, Upton J. Infantile digital fibromas. J Hand Surg [Am]. 1995;20: 1014-20.

25. Federici S, Mordenti M, Domenichelli V, Pelusi G, Straziuso S, Pericoli R. Successful combined treatment for giant mesenteric desmoid tumor: case report and review of the literature. J Pediatr Surg. 2012;47:e25-30.

26. Flacke $S$, Pauleit D, Keller $E$, et al. Infantile fibromatosis of the neck with intracranial involvement: MR and CT findings. AJNR Am J Neuroradiol. 1999;20:923-5.

27. Fowler CB, Hartman KS, Brannon RB. Fibromatosis of the oral and paraoral region. Oral Surg Oral Med Oral Pathol. 1994;77:373-86.

28. Geist ET, Kent JN, Carr RF, Super S. Case 52: Multiloculated radiolucency of the left mandible. J Oral Maxillofac Surg. 1985;43:205-9.

29. Goepfert H, Cangir A, Ayala AG, Eftekhari F. Chemotherapy of locally aggressive head and neck tumors in the pediatric age group. Desmoid fibromatosis and nasopharyngeal angiofibroma. Am J Surg. 1982:144:437-44.

30. Gomez FM, Patel PA, Stuart S, Roebuck DJ. Systematic review of ablation techniques for the treatment of malignant or aggressive benign lesions in children. Pediatr Radiol. 2014;44:1281-9.

31. Hartstein ME, Thomas SM, Ellis LS. Orbital desmoid tumor in a pediatric patient. Ophthal Plast Reconstr Surg. 2006;22:139-41.

32. Hoffman CD, Levant BA, Hall RK. Aggressive infantile fibromatosis: report of a case undergoing spontaneous regression. J Oral Maxillofac Surg. 1993;51:1043-7

33. Jabbari S, Andolino D, Weinberg $V$, et al. Successful treatment of high risk and recurrent pediatric desmoids using radiation as a component of multimodality therapy. Int J Radiat Oncol Biol Phys. 2009:75:177-82.

34. Jacob Cl, Kumm RC. Benign anteromedial plantar nodules of childhood: a distinct form of plantar fibromatosis. Pediatr Dermatol. 2000;17:472-4.

35. Kau CH, Kamel SG, Wilson J, Wong ME. New method for analysis of facial growth in a pediatric reconstructed mandible. Am J Orthod Dentofacial Orthop. 2011;139:e285-90. 
36. Koyluoglu G, Yildiz E, Koyuncu A, Atalar M. Management of an esophagogastric fibromatosis in a child: a case report. J Pediatr Surg. 2004;39:640-2.

37. Kraft SM, Singh V, Sykes KJ, Gamis A, Manalang MA, Wei JL. Differentiating between congenital rhabdomyosarcoma versus fibromatosis of the pediatric tongue. Int J Pediatr Otorhinolaryngol. 2010;74:781-5.

38. Kriss TC, Warf BC. Cervical paraspinous desmoid tumor in a child: case report. Neurosurgery. 1994;35:956-9. discussion 959.

39. Lackner H, Urban C, Benesch M, et al. Multimodal treatment of children with unresectable or recurrent desmoid tumors: an 11-year longitudinal observational study. J Pediatr Hematol Oncol. 2004;26:518-22.

40. Lackner H, Urban C, Kerbl R, Schwinger W, Beham A. Noncytotoxic drug therapy in children with unresectable desmoid tumors. Cancer. 1997;80: 334-40.

41. Lakhan SE, Eager RM, Harle L. Aggressive juvenile fibromatosis of the paranasal sinuses: case report and brief review. J Hematol Oncol. 2008;1:3.

42. Maillard AA, Kountakis SE. Pediatric sino-orbital desmoid fibromatosis. Ann Otol Rhinol Laryngol. 1996;105:463-6.

43. Mannan AA, Ray R, Sharma SC, Hatimota P. Infantile fibromatosis of the nose and paranasal sinuses: report of a rare case and brief review of the literature. Ear Nose Throat J. 2004;83:481-4.

44. Meng J, Zhuang Q, Tian Z, Fu H, He Y. Infantile fibromatosis of the pterygomandibular space. J Craniofac Surg. 2012;23:e542-4

45. Merchant TE, Nguyen D, Walter AW, Pappo AS, Kun LE, Rao BN. Long-term results with radiation therapy for pediatric desmoid tumors. Int J Radiat Oncol Biol Phys. 2000;47:1267-71.

46. Neri HA, Villagra EJ, Alvarez AC, et al. Ethmoidal desmoid tumor in a pediatric patient. Otolaryngol Head Neck Surg. 2007;136:137-8.

47. Otmani N, Lamalmi N, Khattab M. Treatment of submandibular fibromatosis with chemotherapy and surgery. A case report. Minerva Stomatol. 2008;57:133-7.

48. Pena S, Brickman T, StHilaire H, Jeyakumar A. Aggressive fibromatosis of the head and neck in the pediatric population. Int J Pediatr Otorhinolaryngol. 2014;78:1-4

49. Perez-Cruet MJ, Burke JM, Weber R, DeMonte F. Aggressive fibromatosis involving the cranial base in children. Neurosurgery. 1998;43:1096-102.

50. Ramirez RN, Otsuka NY, Apel DM, Bowen RE. Desmoid tumor in the pediatric population: a report of two cases. J Pediatr Orthop B. 2009:1 1:141-4.

51. Reich S, Overberg-Schmidt US, Buhrer C, Henze G. Low-dose chemotherapy with vinblastine and methotrexate in childhood desmoid tumors. J Clin Oncol. 1999;17:1086.

52. Roychoudhury A, Parkash H, Kumar S, Chopra P. Infantile desmoid fibromatosis of the submandibular region. J Oral Maxillofac Surg. 2002;60: 1198-202.

53. Rutenberg MS, Indelicato DJ, Knapik JA, et al. External-beam radiotherapy for pediatric and young adult desmoid tumors. Pediatr Blood Cancer. 2011;57:435-42.

54. Sarin YK, Khurana N. Desmoid tumor of the buttock in a preadolescent child. APSP J Case Rep. 2011;2:2.

55. Sato K, Kawana M, Nonomura N, Takahashi S. Desmoid-type infantile fibromatosis in the mandible: a case report. Am J Otolaryngol. 2000;21: 207-12.

56. Seper $L$, Burger $H$, Vormoor J, Joos U, Kleinheinz J. Agressive fibromatosis involving the mandible - case report and review of the literature. Oral Surg Oral Med Oral Pathol Oral Radiol Endod. 2005:99:30-8.

57. Sharma A, Ngan BY, Sandor GK, Campisi P, Forte V. Pediatric aggressive fibromatosis of the head and neck: a 20-year retrospective review. J Pediatr Surg. 2008:43:1596-604.

58. Shindle MK, Khanna AJ, McCarthy EF, O'Neill PJ, Sponseller PD. Desmoid tumor of the spinal canal causing scoliosis and paralysis. Spine (Phila Pa 1976). 2002;27:E304-7.

59. Sinno H, Zadeh $T$. Desmoid tumors of the pediatric mandible: case report and review. Ann Plast Surg. 2009:62:213-9.

60. Spiegel DA, Dormans JP, Meyer JS, et al. Aggressive fibromatosis from infancy to adolescence. J Pediatr Orthop. 1999;19:776-84.

61. Steuer KS. Pediatric fibromatosis requiring mandibular resection and reconstruction. AORN J. 1995:62:212. 215-224, 226.

62. Styczynski J, Lasek W, Wysocki M. Calcified fibromatosis of the neck in 4-year old girl: rapid growth, rapid therapy. Int J Pediatr Otorhinolaryngol. 2005;69:847-52
63. Tandon S, Garg RK. Intraoral desmoplastic fibroma: a manifestation of tuberous sclerosis. Fetal Pediatr Pathol. 2012;31:195-201.

64. Tostevin PM, Wyatt M, Hosni A. Six cases of fibromatosis of the head and neck in children. Int J Pediatr Otorhinolaryngol. 2000;53:235-44.

65. Tzakis AG, Tryphonopoulos P, De Faria W, et al. Partial abdominal evisceration, ex vivo resection, and intestinal autotransplantation for the treatment of pathologic lesions of the root of the mesentery. J Am Coll Surg. 2003;197:770-6.

66. Wang B, Ma J, Jin H. Infantile intracranial aggressive fibromatosis: report of two cases with a review of the literature. Pediatr Neurosurg. 2012;48:181-6.

67. Wang W, Koirala U, Ma S, et al. Age-based treatment of aggressive fibromatosis in the head and neck region. J Oral Maxillofac Surg. 2014;72:311-21.

68. Watzinger F, Turhani D, Wutzl A, Fock N, Sinko K, Sulzbacher I. Aggressive fibromatosis of the mandible: a case report. Int J Oral Maxillofac Surg. 2005;34:211-3.

69. Wehl G, Rossler J, Otten JE, et al. Response of progressive fibromatosis to therapy with liposomal doxorubicin. Onkologie. 2004;27:552-6.

70. Yazici N, Yalcin B, Soylemezoglu F, et al. Intracranial desmoid tumor with familial adenomatous polyposis coli. Pediatr Neurosurg. 2008:44:140-3.

71. Zampieri N, Cecchetto M, Zorzi MG, Pietrobelli A, Ottolenghi A, Camoglio F. An unusual case of extra-abdominal desmoid tumour. Eur J Cancer Care (Engl). 2010;19:410-2.

72. Zhou Y, Zhang Z, Fu H, Qiu W, Wang L, He Y. Clinical management of pediatric aggressive fibromatosis involving the mandible. Pediatr Blood Cancer. 2012;59:648-51.

73. Arnold DJ, Wax MK. Microvascular Committee of the American Academy of Otolaryngology - Head and Neck Surgery. Pediatric microvascular reconstruction: a report from the Microvascular Committee. Otolaryngol Head Neck Surg. 2007;136:848-51.

74. Bilkay U, Tiftikcioglu YO, Temiz G, Ozek C, Akin Y. Free-tissue transfers for reconstruction of oromandibular area in children. Microsurgery. 2008;28:91-8.

75. Skapek SX, Anderson JR, Hill DA, et al. Safety and efficacy of high-dose tamoxifen and sulindac for desmoid tumor in children: results of a Children's Oncology Group (COG) phase II study. Pediatr Blood Cancer. 2013:60:1108-12.

76. Skapek SX, Ferguson WS, Granowetter L, et al. Vinblastine and methotrexate for desmoid fibromatosis in children: results of a Pediatric Oncology Group Phase II Trial. J Clin Oncol. 2007;25:501-6.

77. Constantinidou A, Jones RL, Scurr M, Al-Muderis O, Judson I. Pegylated liposomal doxorubicin, an effective, well-tolerated treatment for refractory aggressive fibromatosis. Eur J Cancer. 2009;45:2930-4.

78. Garbay D, Le Cesne A, Penel N, et al. Chemotherapy in patients with desmoid tumors: a study from the French Sarcoma Group (FSG). Ann Oncol. 2012;23:182-6.

79. Gounder MM, Lefkowitz RA, Keohan ML, et al. Activity of Sorafenib against desmoid tumor/deep fibromatosis. Clin Cancer Res. 2011;17:4082-90.

80. Penel N, Le Cesne A, Bui BN, et al. Imatinib for progressive and recurrent aggressive fibromatosis (desmoid tumors): an FNCLCC/French Sarcoma Group phase II trial with a long-term follow-up. Ann Oncol. 2011;22:452-7.

81. Nuyttens JJ, Rust PF, Thomas Jr CR, Turrisi 3rd AT. Surgery versus radiation therapy for patients with aggressive fibromatosis or desmoid tumors: A comparative review of 22 articles. Cancer. 2000;88:1517-23.

82. Guadagnolo BA, Zagars GK, Ballo MT. Long-term outcomes for desmoid tumors treated with radiation therapy. Int J Radiat Oncol Biol Phys. 2008;71:441-7.

\section{Submit your next manuscript to BioMed Central and we will help you at every step:}

- We accept pre-submission inquiries

- Our selector tool helps you to find the most relevant journal

- We provide round the clock customer support

- Convenient online submission

- Thorough peer review

- Inclusion in PubMed and all major indexing services

- Maximum visibility for your research

Submit your manuscript at www.biomedcentral.com/submit 